\title{
A Need Analysis of English Learning for the Aircraft Maintenance Students
}

\author{
Fairistya Embryany ${ }^{1, *}$, Ratmanida $^{1}$ \\ ${ }^{I}$ Department of English Education, Faculty of Language and Art, Universitas Negeri Padang, Padang, Indonesia \\ *Email: fairisembry@yahoo.com
}

\begin{abstract}
This research aimed to find out the needs of English learning for the aircraft maintenance students at SMK Penerbangan Nusantara Ketaping. The information of the students' needs were obtained through necessities, wants and lacks. The type of the research was descriptive research. The data were collected from 8 workers and 137 students through two types of questionnaires. The results showed that in this field, the dominant English skill needed was reading and several important topics (necessities). However, there were still some gaps (lacks) between English topics that should be mastered with the topics that the students mastered. Moreover, the students had their preferences (wants) related to the English learning process.
\end{abstract}

Keywords: need analysis, learning needs, ESP, aircraft maintenance

\section{INTRODUCTION}

The vocational graduates have been prepared to work once they finish their study. However, for the past four years the vocational graduates dominated the proportion of the open unemployment according to BPS (Central Agency Statistic) in 2018 [1]. Thus, this situation required the government to find the solutions. One of them is through the Presidential Directive about vocational revitalization. The vocational curriculum must be linked and matched to the needs of the technology and industrial business.

Need analysis is the basis to the link and match strategy. It is a set of activitie where the main goal is to collect information as much as possible to find what the needs of the learners are [2], [3]. All of the information is useful to shape the course. Some experts, such as Dudley-Evans \& John[4]; Hutchinson \& Waters[5] have provided framework in gathering the information which can be a guidance for the course designers to follow. In sum up, it is impossible to have an excellent course which suits the target situation without having need analysis.

According to Hutchinson \& Waters[5], the target needs can be understood through these terms: 1) necessities, the information related to the demands in the target situation, 2) lacks, the information about the gaps between what should be mastered with what have been mastered, and 3) wants, the information related to the students' wants in learning process. The results of these needs can be the basis in determining the materials or the activities in the classroom.

Aviation is an international industry; as a result, it involves multiple languages. However, the International Civil Aviation Organization [6] has established English as the aviation official language. The English used in aviation is different from English for general purposes. Thus, Aviation English is one of the branch of ESP course. Lin, Wang, \&
Zhang[7] mentions that aviation English is one of the subdivisions of ESP (English for Specific Purposes) the same kind as English for Science and Technology (EST), English for Business and Economy (EBE), and English for Social Science (ESS) in the Hutchcinson and Waters's tree. The English used in aviation industry is related to the works done in each division.

One of the divisions in the aviation industry is aircraft maintenance. English needs for the aircraft maintenance are different from other divisions, such as pilots, ATCs, or flight attendants, which are based on the performed tasks. Based on the regulation stated by the Indonesian Ministry of Transportation[8], there are several duties that must be performed by the aircraft maintenance with the main task is to ensure the continuing airworthiness of an aircraft or the aircraft parts. These duties should become the starting point in conducting the teaching and learning process in the aircraft maintenance schools. Therefore, when the students graduate, they will have knowledge about their expertise and they are capable in performing their duties.

SMK Penerbangan Nusantara Ketaping is one of the vocational high school which focuses on producing the professional graduates in the field of aircraft maintaining. As a vocational high school, the English learned should has been specified to the English for specific purposes (ESP) for aircraft maintenance. However, in the teaching and learning process, the English learned was not far different from the English for general purposes (EGP). Thus, it is important to conduct a need analysis. It allows the learners to master skills needed based on the work field. Therefore, the teaching and learning process can focus on the important things which become the priority. Furthermore, it will result on the effectiveness of the course.

This research was conducted in analyzing the needs in learning English for the aircraft maintenance students. The needs were analyzed through these research questions: 1) What were the English necessities (language skills and topics) which were considered important by the aircraft 
maintenance workers?; 2) What were the aircraft maintenance students' wants that might give contributions to the English learning process?; 3) What were the gaps (lacks) between the demands in the work field with the students' current proficiency?

\section{METHOD}

Based on the research questions and objectives of the research, the type of this research was descriptive research. This research investigated the needs in learning English for the aircraft maintenance students. In collecting the data, two types of questionnaires were distributed. The first one was distributed to 8 aircraft maintenance workers and the second one was for137aircraft maintenance students. The questionnaire for the workers was to find out the necessities in learning English, such as the language skills and topics needed. Meanwhile the questionnaire for the students was to find out the lacks and wants aspects. In analyzing the important language skills and topics needed, the Lickert Scale was used with the several categories: Very Important, Important, Less Important, and Not Important. The data related to the students' wants were analyzed by calculating the percentage of each answer in the questionnaire. The answer with the highest percentage was considered to represent the students' actual condition. The gaps (lacks) were analyzed by comparing which topics that had been mastered by the students with the topics needed in the target situation.

\section{RESULTS AND DISCUSSION}

\subsection{The English Necessities for the Aircraft Maintenance}

Necessities is one of the terms used in conducting need analysis. This term aims to reveal the information related to the demands of the target situation Hutchinson, (1987). In this research, the demands of the target situation were divided into language skills and the topics. The data were obtained through the questionnaires distributed to the workers.

According to the workers, all of the English language skills can be categorized as "very important" to be mastered: Reading (97\%), Writing (91\%), Speaking (88\%), and Listening (84\%). It can be inferred that the workers tend to use their reading ability. It was proven by the fact that the main jobs of the maintenance, as they are stated in regulation by the Indonesian Ministry of Transportation, are maintaining and repairing the aircraft. To perform the tasks, the workers must follow certain task card or job card that are in English. Thus, the ability to read is very important for the workers.

There were several English topics that were considered important in this field. These topics should be learned by the students in order to function well in the target situation.
For the listening skills, the topics needed to be mastered were: listening to the instruction, spoken texts (report), understanding conversation, listening to the radio, TV, or other English media, and comprehending presentation or discussion. For the speaking skills, the topics were: presenting report, asking and giving information, giving instruction, describing problems, reporting incidents, making and answering phone call, introducing self, asking and giving opinions, asking and giving direction, and asking and giving suggestion/advices. For the reading topics that should be mastered by the students are: reading technical manual, reading log entries, reading instructions, reading report, statistic data, formal letters, e-mail, journals, announcement, memos, and reading news. Moreover, the important writing topics were: filling the technical log entries, writing $\mathrm{CV}$, statistic data, describing problem, reporting incidents, writing reports, journals, formal letters, announcement, e-mails, and memos.

In conclusion all of the English skills, such as listening, speaking, reading, and writing were important for the target situation. However, the most important skill was reading. Furthermore, for the topics, all of provided topics in the questionnaire can be categorized as important. It means that those topics are needed to be mastered for the target situation.

\subsection{Students' Wants in Learning English}

Wants is another aspect used in conducting need analysis. This aspect was viewed from the learners' standpoint. It is useful to gain information related to ESP situation wanted by the students. However, according to Hutchinson \& Waters[5], not all of the wants can be seen as priority in ESP program. It is quite possible that the learners' wants might contradict with the target situation. Nevertheless, the learners' wants can still give the course designers some insights that might contribute to the English learning process.

In this research, the indicators to reveal the students' wants were adapted from the Hutchinson's framework. They were several categories, such as: the inputs, activities, settings, and teachers' attitude.

The learning input in each language skill, consisted of subcategories, such as type and length. For the listening skill, the type of the input that almost half of the students want was monologue and dialogue with video (46,18\%). Meanwhile, almost the rest of the students $(45,99 \%)$ did not matter whether the monologue and dialogue were with or without a video. For the length of the listening input, the students preferred input which contained about 150 words (short). For the speaking input, more than half of the students $(51.9 \%)$ wanted to learn monologue and dialogue with pictures. About $40,15 \%$ of the students did not matter whether the monologue and dialogue with or without pictures. Moreover, for the length of the speaking input, almost half of the students $(43,07 \%)$ preferred the input consisted of 200 words (medium). For the reading input, the type of the inputs depended on the text they were studying. Furthermore, for the length of the reading inputs, 
almost half of the students wanted a text which consisted of 250-300 words (medium). For the writing input, the students would like to produce a piece of writing after they had learned the related example of the text they were going to produce $(31,15 \%)$. Moreover, the length of the writing that the students wanted to produce consisted of 150-200 words (short). Based on these data, there are some conclusion that can be drawn. First, the most of the students want something creative that can catch their attention in learning. For example, the students preferred videos or pictures for their listening and speaking inputs. It is understandable that it would be more attractive to use these kind of media rather than not using it. Secondly, most of the students favored to have short or medium length of input for each skill rather than the long one. This result might contradict to what the school's want. In the questionnaire, the length of input was based on the regular length in the national exam and in the book used. Therefore, the students' wants related to the length of the input might result on their achievement. In conclusion the course designer must consider thoroughly the students' wants related to the inputs.

For the learning activities, there were several preferences. For listening skill, there were two types of activities that had the same percentage which were preferable for the students such as identifying the text's main idea or topic $(19,35 \%)$ and identifying the detailed information $(19,35 \%)$. Furthermore, for the speaking skill, there most preferable activity was role playing $(19,94 \%)$. For the reading skill, the top activity that students preferred was identifying the text's main idea $(18,60 \%)$. For writing activities, the most favorite activity was practicing writing a text with the appropriate grammar and organization $(21,30 \%)$.It can be assumed that most of the students chose the activities that they usually did in the classroom. For example, usually in listening and reading, the common activities done in the classroom were the finding the topics or the main idea (skimming), finding the specific detailed information (scanning), or answering the questions related to the input texts. Moreover, for the speaking input, the common activities were making dialogue or role playing. It implies that the students find these activities useful for them or, in other words, they believe that these activities can improve their English.

Related to the settings, there were several results. Most of the students preferred to learn in English inside of the classroom $(33,05 \%)$. It might be the one of the places where they can study comfortably and efficiently. However, surprisingly, many of them would also love to study outside of the classroom $(30,90 \%)$, such as on the class terrace, park or school hall. It implied that they preferred non-monotonous circumstance. Furthermore, related to the way in doing assignment, many of the students liked to work in a group. They preferred a group consisted of 3-4 members $(34,04 \%)$ or a pair $(31,06 \%)$ rather than a bigger group (5-8 members) $(11,91 \%)$. It might be due to the consideration that bigger groups might less effective than smaller groups. However, it is interesting to see that many of the students also preferred working alone $(22,98 \%)$. These students might think that working alone is more effective than working in group. During the learning process, there are two interesting points. First, the students would love to have discussion and actively participate in solving the problems and tasks $(25,67 \%)$. This situation indicated that many students preferred to become the center in the teaching and learning process. This situation perfectly fits with our current curriculum where the teaching and learning process should be based on the student-oriented. However, the many other students still preferred to be guided by the teachers $(24,52 \%)$ which indicated that many of them were not ready to be actively participated in the learning process.

The students had certain preferences related to the English teacher. An English teacher who has the ability to create conducive atmosphere for students to be actively involved in solving the problems and tasks was the type of a teacher that the students want $(25,96 \%)$. This kind of need really meets the previous finding where, in doing activities, the students liked to be actively involved in the learning process. Thus, they also need a teacher who could create such circumstance. Furthermore, related to the "lingua franca" in the classroom, almost all of the students wanted the same thing $(83,21 \%)$. It was a teacher who used both language, English and Indonesian. This choice shows that the students wanted a teacher that can be the real model in practicing English. Lastly, related to the teachers' background, $71,53 \%$ of the students believe that the best teacher for them was the one who both master English and understand their aircraft maintaining field. It is common knowledge that English used in the mechanical engineering somewhat different from general English, in the term of discourse or technical words used. Thus, it can be assumed that the students want a teacher who could understand the difference by mastering English in their field.

In sum up, the data gathered from this research provide many information related to the students' wants. Not all of these wants should be taken and made as priorities. However, they still provide some knowledge that can be beneficial to the English teaching and learning process.

\subsection{The Gaps (Lacks)}

Lacks is also one of the aspect in conducting need analysis. To find the lacks, the necessities and the current knowledge should be analyzed. In other words, the gaps between what have been known or mastered with what should be known or mastered in the target situation are called lacks. In this research to find out the lacks, the students were also asked to determine which topics that they sure they had mastered. Then, the information was compared to the necessities data from the workers.

For the listening topics, 73 out of 137 students $(33,49 \%)$ claimed that they had mastered the topic related to listening the instruction. When these information compared to the necessities or the topics needed, there are still some topics that still need to be mastered, such as comprehending the presentation, comprehending the oral report, understanding conversation, and listening to the radio or TV. (s) 


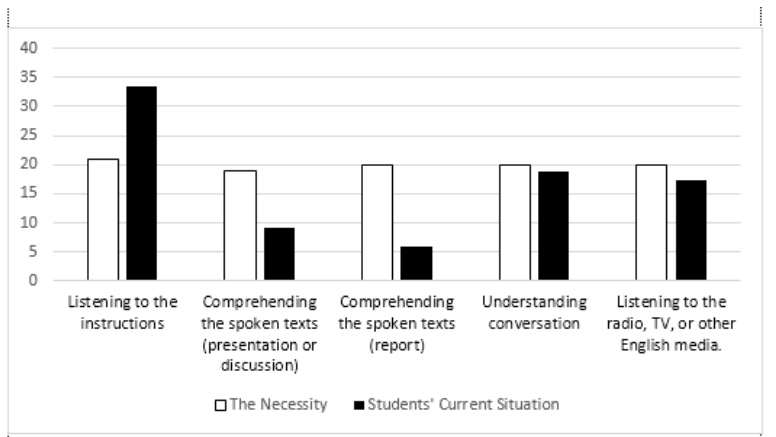

Figure 1 The Listening Topics Mastered by the Students Compared to the Necessities

For the speaking topic, almost all of the students (128 out of 137 students) believed that they could introduce themselves in English. It proves that this topic was the easiest topic to master. Another speaking topics that were mastered by many students was giving instruction (53 out of 137 students) and asking and giving suggestion/advice (52 out of 137 students). Besides the fact that almost all of the students seemed to master the topic about introducing self, it can be seen clearly that some of the important topics had not been mastered by the students, such as reporting incident, presenting report, and describing problems. These three important topics were in top-five of the important topics that are needed for the target situation. It means that to function effectively in the target situation, the students must learn these topics.

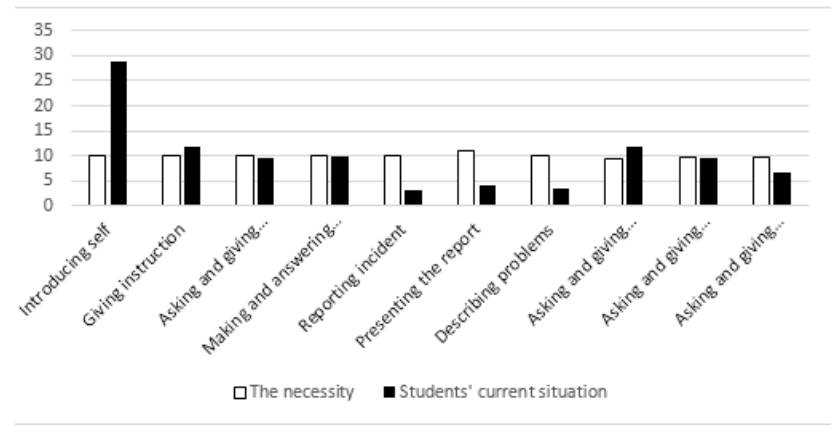

Figure 2 The Speaking Topics Mastered by the Students Compared to the Necessities

Furthermore, the result from the reading and writing skills has a common. Announcement became the topic that was mostly mastered by the students. It was proven by the highest percentages of this topics in each skill: reading announcement (68 out of 137 student) and writing announcement (64 out of 137 students). Moreover, it can be concluded that many had mastered half of the topics. However, they had not mastered the important topics ones, such as the technical manual, log entries, statistic data, and describing problems which are needed for the target situation.

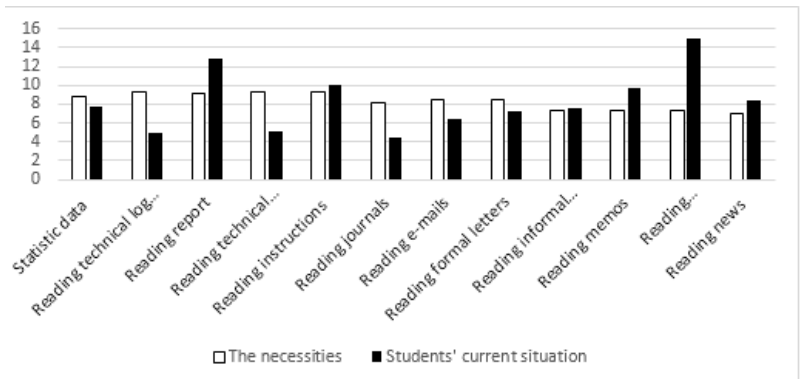

Figure 3 The Reading Topics Mastered by the Students Compared to the Necessities

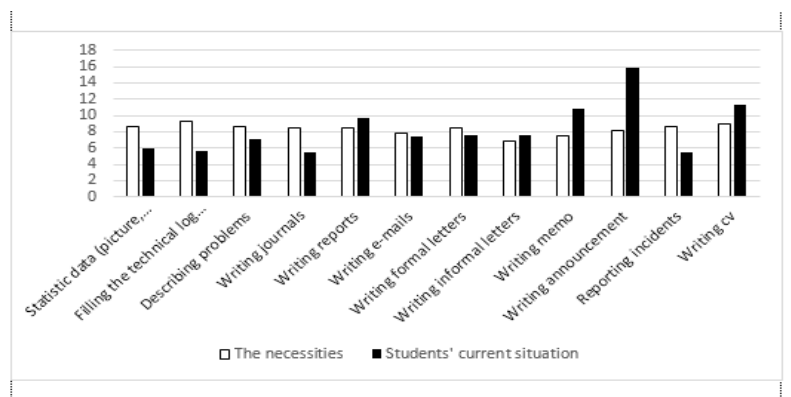

Figure 4 The Writing Topics Mastered by the Students Compared to the Necessities

\section{CONCLUSION}

In this research, there are several points that can be concluded. Related to the necessities, the most important skill to be mastered by this field was reading since most of their tasks required reading ability. Next, there were many important topics for each language skill. Those topics had their own priority based on their importance in the target situation. Thirdly, it is related to the students' wants in learning English. Although not all of the wants could become the priorities, they still gave contribution by providing the information that could support the teaching and learning process. Lastly, it is related to the students' lacks. Overall, the students still had some lacks related to the topics that should be mastered. However, these lacks can give useful information about what should be done to prepare the students for the target situation.

\section{REFERENCES}

[1] BPS, Tingkat Pengangguran Terbuka. 2018.

[2] K. Hyland, English for Academic Putposes: An Advanced Resources Book. London: Routledge, 2006.

[3] H. Basturkmen, Ideas and Opinion in English for Specific Purposes. New Jersy: Lawrence Erlbaum Associates, 2006.

[4] T. Dudley-Evans and M. Jo St John,

"Developments in English for Specific Purposes. A MultiDisciplinary Approach," Ibérica, vol. 0, pp. 521-59329, 1998. 
Aviation English for Aircraft Engineering," Open J. Mod.

[5] T. Hutchinson and A. Waters, English for Specific Purposes. New York: Cambridge University Press, 1987.

[6] ICAO, Manual on the Implementation of ICAO Language Proficiency Requirements. Canada: University Street, Montréal, 2010.

[7] J. Lin, A. Wang, and C. Zhang, "Integrating Curriculum Design Theory into ESP Course Construction:
Linguist., vol. 04, no. 02, pp. 219-227, 2014.

[8] Indonesian Ministry of Transportation, Peraturan Menteri Perhubungan No. PM 64 2011. 2011. 